\title{
Foliar Fungicides as Protective Seed Piece Treatments for Management of Late Blight of Potatoes
}

Mary L. Powelson, Department of Botany and Plant Pathology, Oregon State University, Corvallis 97331-2902; and Debra A. Inglis, Washington State University-Mount Vernon Research and Extension Unit, 16650 State Route 536, Mount Vernon 98273-9761

\begin{abstract}
Powelson, M. L., and Inglis, D. A. 1999. Foliar fungicides as protective seed piece treatments for management of late blight of potatoes. Plant Dis. 83:265-268.

Fungicides receiving Section 18 emergency exemptions for management of the foliar phase of late blight of potato were evaluated as protective treatments for control of tuberborne inoculum of Phytophthora infestans in greenhouse and field studies. Three Section 18 products, Acrobat MZ (dimethomorph + mancozeb), Curzate M-8 (cymoxanil + mancozeb), and Tattoo C (propamocarb hydrochloride + chlorothalonil), when applied to the seed piece prior to inoculation with $P$. infestans, significantly $(P \leq 0.05)$ increased sprout emergence, compared with the inoculated water control. Of the three Section 18 products, Curzate M- 8 was frequently the most effective. The increase in plant emergence with the protective seed piece treatment was seen with cultivars that differ in susceptibility to late blight, two genotypes (US-8 and US-11) of $P$. infestans, zoospore and sporangial inocula, and at different inoculation sites on the seed piece. In greenhouse studies, percent emergence with the protective seed piece treatments averaged $74 \%$ for cv. White Rose and $44 \%$ for cv. Shepody, compared with 9 and $8 \%$ for the inoculated water control of the respective cultivars. In field studies, when inoculum was placed either adjacent to or $4 \mathrm{~cm}$ away from the sprout, plant emergence of the inoculated water control was 12 and $36 \%$, respectively. Application of the fungicides to the seed piece prior to inoculation increased emergence by an average of 700 and $212 \%$ for the respective inoculation sites. There was no evidence for translocation of the fungicides to the emerging foliage in concentrations high enough to prevent foliar infection from airborne inoculum of $P$. infestans. Control of tuberborne inoculum of $P$. infestans with appropriate seed piece treatments will result in an increase in plant emergence and improved crop uniformity.
\end{abstract}

Additional keywords: Solanum tuberosum, tuber blight

Planting of seed tubers contaminated with Phytophthora infestans (Mont.) de Bary is reported to initiate late blight epidemics in the field $(12,14)$. New immigrant clones of $P$. infestans, such as US-6, US-8, and US-11 that are resistant to the fungicide metalaxyl, have displaced the previous US-1 clonal population of $P$. infestans (7, 8 ) and are more aggressive on tubers and sprouts than the previously established US1 clonal lineage $(14,16$; D. A. Inglis, unpublished data). In a greenhouse study in which transmission efficiency of US-1 and US-8 from seed piece to sprout was compared, US-1 produced only $1.9 \%$ diseased sprouts, compared with $19.4 \%$ for US-8 (16). Such observations affirm the importance of tuberborne inoculum of these new clones in the epidemiology of late blight.

Corresponding author: M. L. Powelson
E-mail: powelsom@bcc.orst.edu

Technical paper 11348 of the Oregon Agricultural Experiment Station.

Accepted for publication 30 November 1998.

Publication no. D-1999-0111-01R

(C) 1999 The American Phytopathological Society
Several fungicide products are registered for control of tuberborne pathogens of potatoes such as Fusarium, Helminthosporium, and Rhizoctonia spp. Some of these fungicides have little to no activity against $P$. infestans (11). Until now, no fungicide has been registered as a seed piece treatment for control of tuberborne inoculum of $P$. infestans (11). Recently, the EPA approved Section 18 emergency requests from many states for the use of products containing three chemistries (cymoxanil, dimethomorph, and propamocarb hydrochloride) for the control of the foliar phase of late blight. These products provide control of foliar symptoms when applied in a protective spray program. Control of foliar symptoms, however, did not result in control of tuber blight (9).

We were interested in whether these same compounds, which have both protectant and systemic activity $(1,16)$, when applied to the seed piece have activity against tuberborne and foliar inoculum of $P$. infestans. Therefore, our objective was to evaluate under greenhouse and field conditions efficacy of Section 18 products as protective seed piece treatments for control of tuberborne and foliar inoculum of $P$. infestans.

\section{MATERIALS AND METHODS}

Inoculum. Phytophthora infestans US-8 (A2, metalaxyl insensitive) in Oregon and US-11 (A1, metalaxyl insensitive) in Washington were used in this study. Inoculum was produced by growing the isolate on rye agar at $18^{\circ} \mathrm{C}$ for 10 to 14 days (Oregon) (3) or on detached potato leaves on moistened filter paper in glass petri dishes at $18^{\circ} \mathrm{C}$ (Washington). Plates were flooded with $5 \mathrm{ml}$ of distilled water and gently agitated (Oregon) or leaves were washed in $25 \mathrm{ml}$ of distilled water (Washington) to release sporangia. The sporangial suspension was adjusted with distilled water to the desired concentration for each experiment. For zoospore inoculum, the flooded plates were placed at $4^{\circ} \mathrm{C}$ for $2 \mathrm{~h}$ to release zoospores.

Fungicides. Seed piece treatment products included Acrobat MZ (dimethomorph + mancozeb; American Cyanamid, Parsippany, NJ), Curzate M-8 (cymoxanil + mancozeb; DuPont Ag Products, Wilmington, DE), and Tattoo $\mathrm{C}$ (propamocarb hydrochloride + chlorothalonil; AgrEvo USA, Wilmington, DE). Seed pieces were soaked for $15 \mathrm{~min}$ in a suspension of the fungicide (10 $\mathrm{g}$ a.i./liter) or in distilled water and dried overnight at room temperature. Fungicide treatments were applied prior to inoculation with $P$. infestans.

Fungicide evaluation experiment. Certified seed potatoes (Solanum tuberosum L.) of cvs. White Rose and Shepody in both Oregon and Washington were cut with a melon ball scoop into single eye seed pieces weighing approximately $15 \mathrm{~g}$. Seed pieces were healed at room temperature for $48 \mathrm{~h}$ and then treated with either a fungicide or distilled water. A $50-\mu 1$ droplet containing approximately 7,000 zoospores (Oregon), 250 sporangia (Washington), or distilled water was placed in the small hole that was made near the sprout with a 200$\mu \mathrm{l}$ pipette tip.

Single seed pieces were planted $6 \mathrm{~cm}$ deep in steam-pasteurized greenhouse potting mix (Oregon) or in moistened commercial potting mix (Washington) in 10$\mathrm{cm}$-diameter $\times 7$ - or 10 -cm-deep pots. Immediately after planting, containers were lightly watered. Treatments were arranged in a randomized block design with 10 replications and included Acrobat MZ, Curzate M-8, Tattoo C, and the inoculated and noninoculated water controls. Each treatment/replication had five seed pieces. Pots 
were kept on a greenhouse bench at a temperature of $17^{\circ} \mathrm{C}$ day $/ 15^{\circ} \mathrm{C}$ night. Beginning at 4 weeks and continuing for another week, data on plant emergence were collected and plants were observed for symptoms of late blight. At 5 weeks, height of emerged plants was measured. The experiment was conducted first with $\mathrm{cv}$. White Rose and later with cv. Shepody.

Site of inoculation $\times$ fungicide experiment. Certified seed potatoes of cvs. Russet Norkotah in Oregon and Shepody in Washington were cut with a knife into single eye seed pieces and then treated with the fungicide as described above. Seed pieces were air dried on a greenhouse bench overnight. A small hole was made with a $200-\mu l$ pipette tip adjacent to the sprout or at a distance of approximately 4 $\mathrm{cm}$ from the sprout. A 50- $\mu$ d droplet containing 350 sporangia (Oregon) or 250 sporangia (Washington) of $P$. infestans or distilled water was placed in the wound.

Field plots were established at the North Willamette Research and Extension Center near Aurora, OR, and at the Washington State University Research and Extension Unit, Mount Vernon, WA, in July of 1997. The experiment was a factorial with fungicide and site of seed piece inoculation as the main effects. The fungicide seed piece treatments (no fungicide, Acrobat MZ, Curzate M-8, or Tattoo C) and site of inoculation (adjacent to or $>4 \mathrm{~cm}$ from bud) were arranged in a randomized complete block design and had five replications. Number of seed pieces per treatment/replication was 12 (Oregon) and 15 (Washington). The one-row plots were $3 \mathrm{~m}$ long in Oregon and $3.8 \mathrm{~m}$ long in Washington. The within-row spacing was $23 \mathrm{~cm}$ and between-plot spacing was $86 \mathrm{~cm}$ in Oregon and $96 \mathrm{~cm}$ in Washington. Cultural practices for both sites were similar to those used commercially in the respective production areas.

At each location data on percent emergence were collected; individual plants were observed for symptoms of late blight on sprouts and then foliage and stems beginning at emergence. Blank hills were hand dug and the seed piece was evaluated for decay. Plots were harvested in Washington and tuber yield was determined.

Fungicide translocation experiment. Certified seed potatoes of cvs. White Rose and Shepody in both Oregon and Washington were cut with a melon ball scoop into single eye seed pieces weighing approximately $15 \mathrm{~g}$. Seed pieces were kept at room temperature for $48 \mathrm{~h}$ to heal, then treated with a fungicide or distilled water as described above and allowed to air dry at room temperature. Individual seed pieces were planted $6 \mathrm{~cm}$ deep in either steam-pasteurized greenhouse potting mix or moistened commercial potting mix in 10 -cm-diameter $\times 7$ - or 10 -cm-deep plastic pots. Immediately after planting, containers were watered. The fungicide treat-

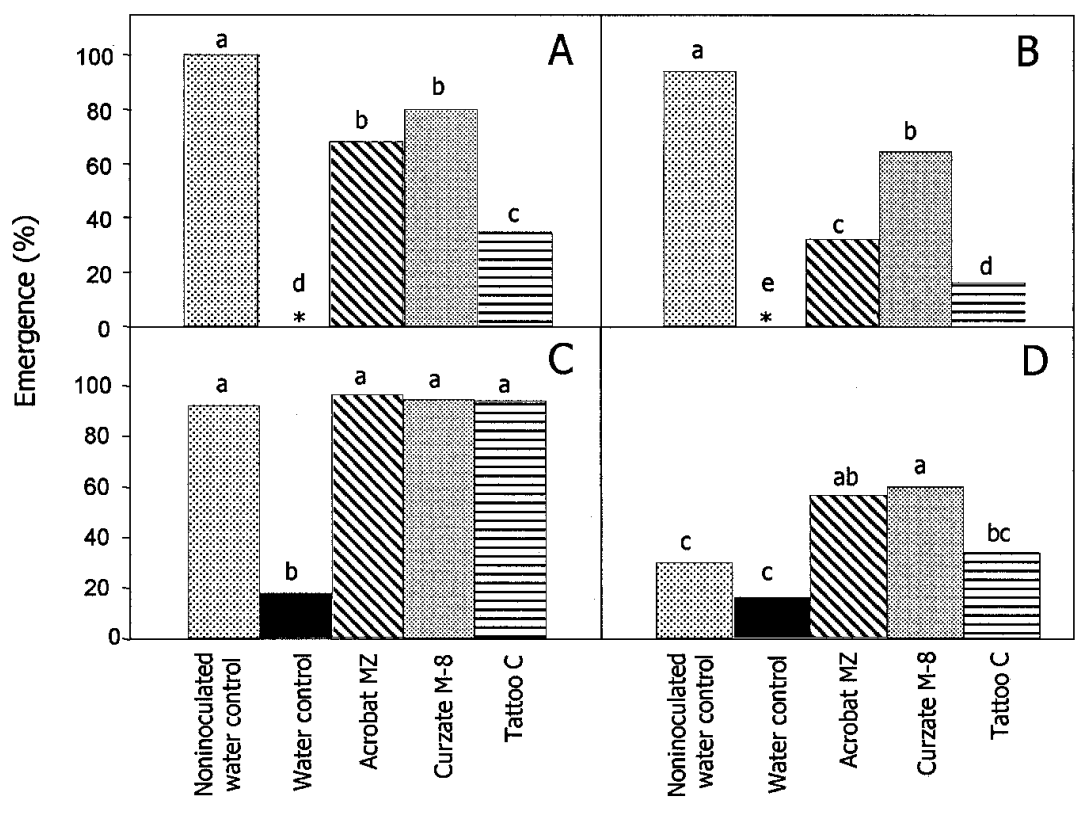

Seed piece treatments

Fig, 1. Efficacy of Section 18 fungicides as seed piece treatments on emergence of Phytophthora infestans-inoculated potato seed pieces in the greenhouse for (A) cv. White Rose in Oregon, (B) cv. Shepody in Oregon, (C) cv. White Rose in Washington, and (D) cv. Shepody in Washington. Fungicides were applied to seed pieces prior to inoculation with P. infestans. Zoospores of US-8 and sporangia of US-11 were used as inocula in Oregon and Washington, respectively. $*=0 \%$ emergence. Bars with the same letter are not significantly $(P>0.05)$ different according to Fisher's protected least significance difference. ments, Acrobat MZ, Curzate M-8, Tattoo $\mathrm{C}$, and the water control, were arranged in a randomized block design with 10 replications. Each treatment/replication had five seed pieces. Pots were held on a greenhouse bench at a temperature of $17^{\circ} \mathrm{C}$ day $/ 15^{\circ} \mathrm{C}$ night. When the plants had one fully expanded leaf an aqueous sporangial suspension $\left(10^{3}\right.$ sporangia per $\left.\mathrm{ml}\right)$ of US-8 in Oregon and US-11 in Washington was applied to the expanded leaf to runoff with an airbrush sprayer. Leaves were allowed to dry before plants were placed in a mist chamber. Mist was applied every $15 \mathrm{~min}$ for $20 \mathrm{~s}$ for $48 \mathrm{~h}$ (Oregon) or applied every $5 \mathrm{~min}$ for $2.5 \mathrm{~s}$ for 4 days (Washington). The inoculated leaf was evaluated for symptoms of late blight on a scale of 1 to 5 in which $1=$ leaf healthy and $5=$ leaf dead (Oregon), or the plant was evaluated for percent blighted foliage (Washington).

Data analysis. The SAS general linear models procedure (Statistical Analysis Systems, SAS Institute, Cary, NC) was used to perform analysis of variance on percent emergence at each location and tuber yield in Washington. Means were separated by Fisher's protected least significant difference test.

\section{RESULTS}

Fungicide evaluation experiment. Treatment of seed pieces with any one of the Section 18 products resulted in a significant $(P \leq 0.05)$ increase in plant emergence compared with the inoculated water control in the greenhouse (Fig. 1A-D). Emergence of cvs. White Rose and Shepody was 2 to 2.5 times higher with Acrobat $\mathrm{MZ}$ and Curzate $\mathrm{M}-8$, respectively, compared with Tattoo $\mathrm{C}$ in Oregon. In Washington, emergence of the inoculated and water treated seed pieces of cv. Shepody was very low. With seed piece treatment, however, emergence was significantly higher $(P \leq 0.05)$, compared with the nontreated controls, and with Acrobat and Curzate M-8 emergence was two times higher compared with Tattoo C. In contrast, there were no differences among fungicide products with cv. White Rose. In Oregon, application of Acrobat MZ or Curzate M-8 also significantly $(P \leq 0.05)$ increased plant height of cv. White Rose; plants were approximately two and three times taller with these two products, respectively, than the plants from the Tattoo $\mathrm{C}$ treatment (data not shown). None of the fungicides had an effect on plant height of Shepody.

Site of inoculation $\times$ fungicide experiment. The fungicide $x$ site of seed piece inoculation interaction was significant $(P \leq 0.05)$ for both plant emergence and tuber yield (Fig. 2A, B; Fig. 3). Curzate M-8 was equally effective in increasing plant emergence at both sites of seed piece inoculation whereas both Acrobat MZ and Tattoo $\mathrm{C}$ were significantly less effective than Curzate M-8 when the in- 
oculation site was adjacent to the sprout. A similar response was observed for tuber yield (Fig. 3). Curzate M-8 was effective in enhancing total tuber yield regardless of inoculation site, whereas the other two fungicides were not as effective when the inoculation site was adjacent to the bud.

Seed piece treatment with a Section 18 product resulted in a significant $(P \leq 0.05)$ increase in plant emergence in the field (Fig. 2A and B). When the inoculation site was adjacent to the sprout, emergence of cv. Russet Norkotah in Oregon was increased 170, 275, and 110\% with Acrobat MZ, Curzate M-8, and Tattoo C, respectively, compared with the inoculated water control. In Washington with cv. Shepody, these same respective fungicides increased emergence by $1,200,2,133$, and $200 \%$ compared with the inoculated water control. When the inoculation site was $4 \mathrm{~cm}$ away from the sprout, the response from seed piece treatment was not as dramatic. Percent increase in emergence was 28, 20, and $20 \%$, respectively, for Acrobat, Curzate M-8, and Tattoo C in Oregon and 433, 475 , and $267 \%$ in Washington. The increase in emergence was associated with a decrease in seed piece decay. Plant vigor was slightly more robust with all the fungicide treatments compared with the nontreated inoculated control. Transmission of $P$. infestans from the seed piece to the developing sprout was not detected.

Site of inoculation affected sprout viability, i.e., when the distance of inoculation site from the sprout was approximately $4 \mathrm{~cm}$, viability of the sprout was increased and hence rate of emergence was higher (Fig. 2A and B). When inoculum was applied next to the sprout, percent emergence in the inoculated water control was 20 and $3 \%$ whereas, at $4 \mathrm{~cm}$ from the sprout, emergence averaged 60 and $12 \%$ for cvs. Russet Norkotah (Oregon) and Shepody (Washington), respectively.

Fungicide translocation experiment. None of the fungicides applied to the seed piece gave protection of emerging foliage against airborne inoculum of $P$. infestans. Average disease severity in Oregon was $3.8,4.4,4.2$, and 4.3 , and percent foliage attacked in Washington was 38, 35, 47, and $42 \%$ for Acrobat MZ, Curzate M-8, Tattoo $\mathrm{C}$, and the water control, respectively.

\section{DISCUSSION}

Protective applications of all three Section 18 products to healthy seed pieces prior to inoculation with $P$. infestans significantly increased sprout emergence compared with the inoculated water control. This response was seen with cultivars that differ in their susceptibility to late blight, two genotypes of $P$. infestans representing both A1 and A2 mating types, zoospore and sporangial inocula, and at two different seed piece inoculation sites.

The impact of seed piece treatment was influenced by cultivar. The magnitude of
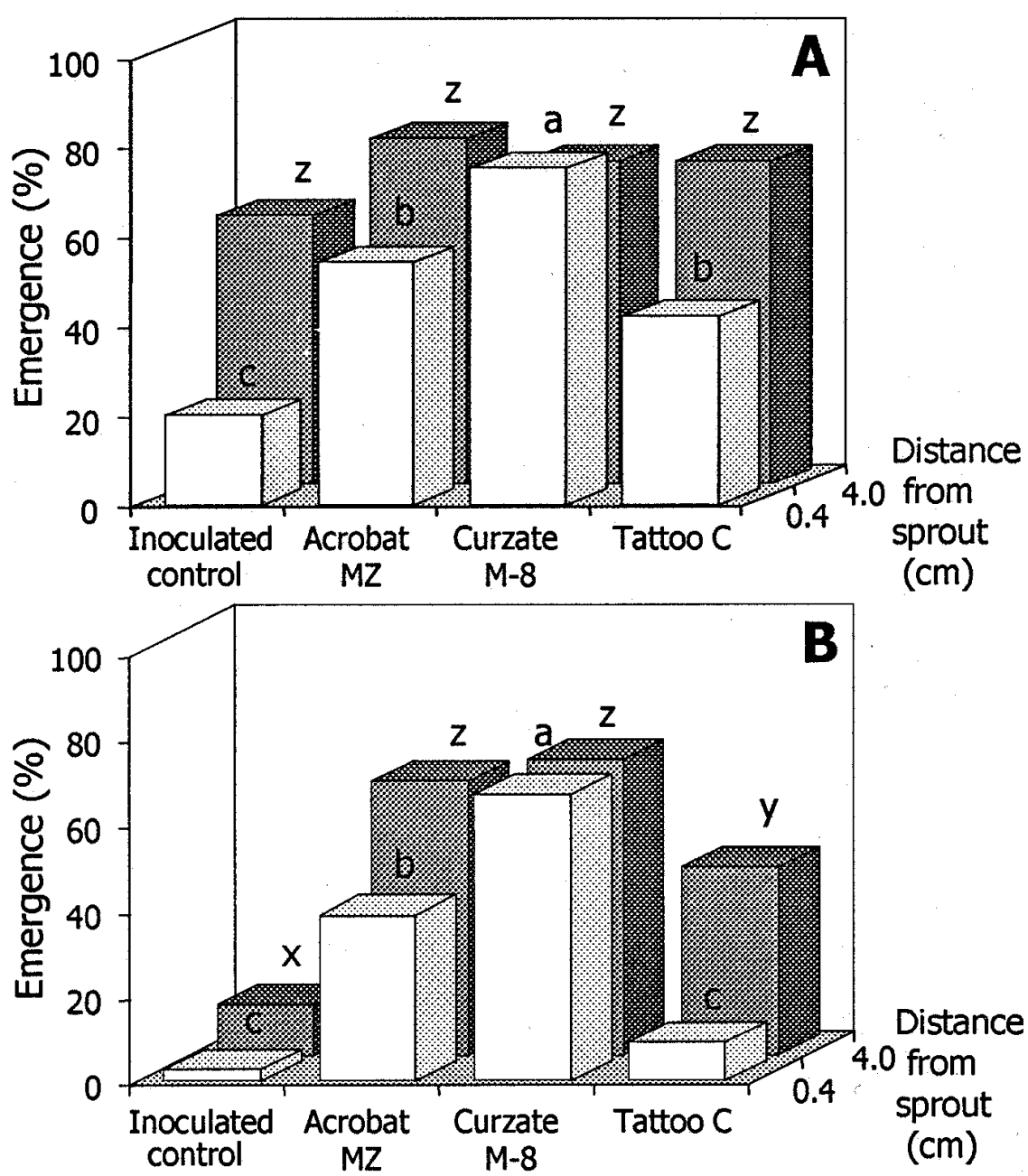

Fig. 2. Fungicide seed piece treatment $\times$ site of Phytophthora infestans inoculation interaction on emergence of potato in the field in (A) Oregon and (B) Washington. Genotypes of P. infestans and potato cultivar were US-8 and Russet Norkotah in Oregon and US-11 and Shepody in Washington, respectively. Bars with the same letter within inoculation site are not significantly $(P>0.05)$ different according to Fisher's protected least significant difference.

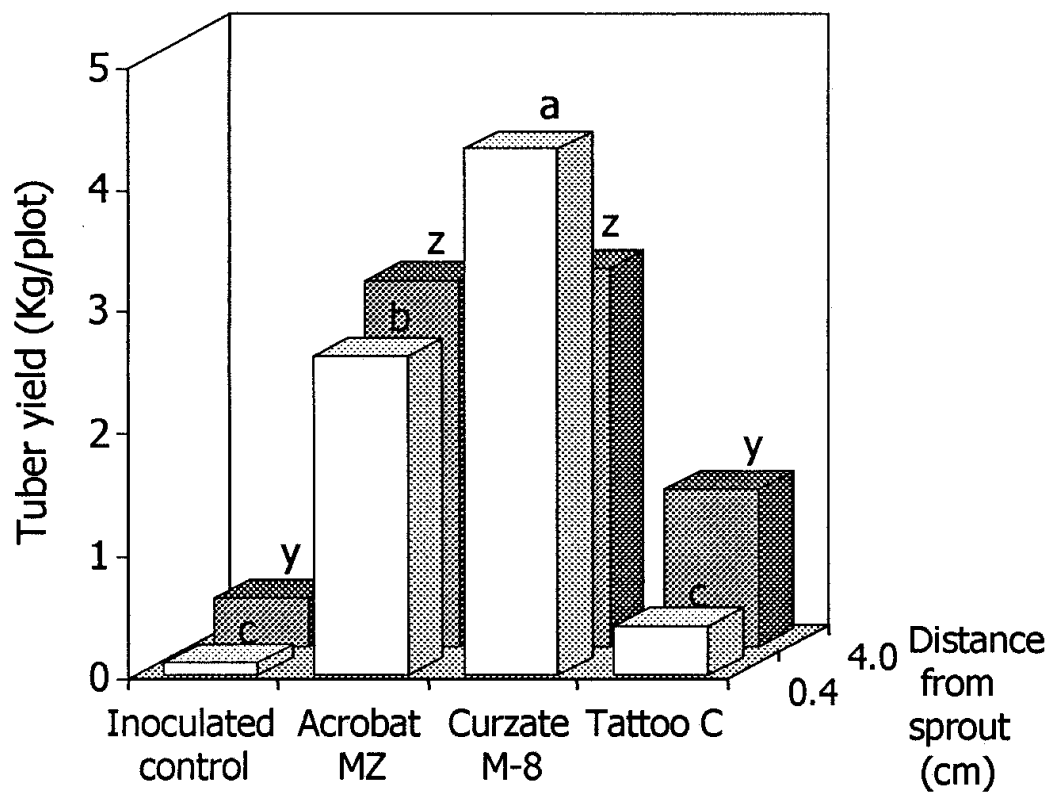

Fig. 3. Fungicide seed piece treatment $\times$ site of Phytophthora infestans inoculation interaction on tuber yield of potato in Washington. Genotypes of $P$. infestans and potato cultivar were US-11 and Shepody, respectively. Bars with the same letter within inoculation site are not significantly $(P>$ 0.05) different according to Fisher's protected least significant difference. 
the response was greater with cv. White Rose than with cv. Shepody. Average percent emergence following seed piece treatment for cv. White Rose was $74 \%$, compared with $44 \%$ for cv. Shepody. Shepody is highly susceptible to both the foliar and tuber phases of the disease $(4,5,10)$. Its susceptibility to late blight tuber rot and seed piece decay is probably responsible, in part, for its lower rate of emergence despite seed piece treatment. In addition, its low emergence in Washington (Fig. 1D) was due, in part, to age of seed tubers and inadequate storage conditions.

Although two kinds of inoculum (zoospores and sporangia) were used in our greenhouse studies, all three fungicides were effective in increasing plant emergence. Both dimethomorph and propamocarb hydrochloride have been reported to be more effective against zoospore than sporangial inoculum of $P$. infestans $(1,17)$. Whether zoospores or sporangia within a clone or genotype will respond differentially to these fungicides is unknown at this time; however, significant differences among isolates of US-1, US-6, US-7, and US-8 clonal lineages for degree of sensitivity to mancozeb or chlorothalonil have been reported (13).

Late blight caused by US- 8 or US- 11 was not observed on any of the emerging sprouts in either the greenhouse or field studies. According to Lambert and Currier (14), the recent immigrant clones of $P$. infestans such as US-6 and US- 8 are more aggressive in tuber tissue than are isolates of the US-1 clone. Moreover, sprouts of most commercial potato cultivars are susceptible to infection by $P$. infestans (4). Aging and light exposure, however, can increase the resistance of the sprouts, and sprout infections can remain dormant even after stem elongation (2). We terminated the experiments within 5 weeks of planting in the greenhouse studies and prior to row closure in the field study because of external sources of inoculum moving into the plots.

During the seed handling process, spores of the late blight pathogen can be brought into contact with many areas on the tuber surface (15). In addition to infecting the sprout directly, $P$. infestans can attack seed pieces through bruises and wounds made during the cutting and handling phases of seed preparation (6). In our experiments, when the inoculation site was not adjacent to the sprout, emergence of nontreated seed pieces averaged $25 \%$ higher than when the inoculation site was next to the sprout. Therefore, if seed piece treatments are to be effective, all points of potential pathogen ingress into the tuber must be protected. Although all three of the Section 18 products were effective in protecting both the tuber surface and sprouts, and each has protectant and limited systemic activity, cymoxanil + mancozeb (Curzate M-8) frequently outperformed the other two products tested. None of the fungicides was effective as a seed piece treatment against airborne spores of $P$. infestans.

Effective control of $P$. infestans on seed pieces can increase the rate of emergence and contribute to crop uniformity. For a seed piece treatment to be effective, however, the fungicide must have activity against $P$. infestans and be in place prior to arrival of inoculum (11). If an appropriate seed piece treatment is applied to healthy seed pieces prior to contamination with $P$. infestans, transmission of the pathogen from seed to the sprout may be reduced, thereby providing growers with a wider window in which to begin foliar fungicide application programs. Application of Section 18 fungicides to diseased seed pieces was not part of this study. Curative applications should not be viewed as an acceptable practice in late blight management programs at this time. Research comparing the effect of appropriate fungicide seed piece treatments on diseased versus contaminated seed tubers in the epidemiology of foliar late blight epidemics is warranted.

\section{ACKNOWLEDGMENTS}

This research was supported, in part, by grants from the National Potato Council, the Oregon Potato Commission, and the Washington State Potato Commission. We thank B. Gundersen, V. Heffer, and R. Ludy for technical and statistical assistance, and Cindy O'Camb and Phil Hamm for their thoughtful reviews of the manuscript.

\section{LITERATURE CITED}

1. Cohen, Y., Baider, A., and Cohen, B.-H. 1995. Dimethomorph activity against oomycete fungal plant pathogens. Phytopathology 85: 1500-1506.

2. Deahl, K. D. 1995. Potato tuber's role in the late blight complex. Pages 10-16 in: Proc.
Annu. Potato Counc. Seed Sem., 14th.

3. Deahl, K. L., Inglis, D. A., and DeMuth, S. P. 1993. Testing for resistance to metalaxyl in Phytophthora infestans isolates from northwestern Washington. Am. Potato J. 70:779795.

4. Dorrance, A. E., and Inglis, D. A. 1997. Assessment of greenhouse and laboratory screening methods for evaluating potato foliage for resistance to late blight. Plant Dis. 81: 1206-1213.

5. Dorrance, A. E., and Inglis, D. A. 1998. Assessment of laboratory methods for evaluating potato tubers for resistance to late blight Plant Dis. 82:442-446.

6. Dowley, L. J., and O'Sullivan, E. O. 1991. Sporulation of Phytophthora infestans (Mont.) de Bary on the surface of diseased potatoes and tuber to tuber spread during handling. Potato Res. 34:295-296.

7. Fry, W. E., and Goodwin, S. B. 1997. Reemergence of potato and tomato late blight in the United States. Plant Dis. 81:1349-1357.

8. Goodwin, S. B., Cohen, B. A., Deahl, K. L., and Fry, W. E. 1994. Migration from northern Mexico as the probable cause of recent genetic changes in populations of Phytophthora infestans in the United States and Canada. Phytopathology 84:553-558.

9. Inglis, D. A., Gundersen, B. M., Ludy, R. L., and Powelson, M. L. 1998. Results of the North American late blight fungicide trial. (Abstr.) Am. J. Potato Res. 75:279.

10. Inglis, D. A., Johnson, D. A., Legard, D. E., Fry, W. E., and Hamm, P. B. 1996. Relative resistances of potato clones in response to new and old populations of Phytophthora infestans. Plant Dis. 80:575-578.

11. Inglis, D. A., Powelson, M. L., and Dorrance, A. E. 1999. Effect of registered potato seed piece fungicides on tuber-borne Phytophthora infestans. Plant Dis.83:000-000.

12. Kadish, D., and Cohen, Y. 1992. Overseasoning of metalaxyl-sensitive and metalaxylresistant isolates of Phytophthora infestans in potato tubers. Phytopathology 82:887-889.

13. Kato, M., Mizubuti, E. S., Goodwin, S. B., and Fry, W. E. 1997. Sensitivity to protectant fungicides and pathogenic fitness of clonal lineages of Phytophthora infestans in the United States. Phytopathology 87:973-978.

14. Lambert, D. H., and Currier, A. I. 1997. Differences in tuber rot development for North American clones of Phytophthora infestans. Am. Potato J. 74:39-43.

15. Lambert, D. H., Currier, A. I., and Olanya, M 1998. Transmission of Phytophthora infestans in cut potato seed. Am. J. Potato Res. 75:257263.

16. Marshall, K. D., and Stevenson, W. R. 1996. Transmission of Phytophthora infestans from infected seed potato tubers to developing sprouts. Am. Potato J. 73: 370-371.

17. Samoucha, Y., and Cohen, Y. 1990. Toxicity of propamocarb to the late blight fungus on potato. Phytoparasitica 18:27-40. 